\title{
Learning Chemistry in a Metacognitive Environment
}

\author{
Richard Pulmones \\ St. Scholastica's College, Philippines
}

\begin{abstract}
Thinking about one's own thinking and of how one learns and solves problems is described as metacognition. The important dimensions of metacognition are knowledge of one's own thinking as one plans, monitors, and evaluates academic tasks. This paper presents a qualitative study on metacognition, on how academic tasks in Chemistry are designed and structured in a constructivist environment that promotes students' metacognitive behaviors and meaningful learning of Chemistry. Sample metacognitive profiles of two cases (low and high metacognitive index), generated from analyses of various qualitative data are also presented. As a conclusion, the paper reiterates a research finding which indicates that prolonged engagement of students in classroom activities designed in a constructivist environment gives ample opportunities for students to demonstrate their overt planning, monitoring and evaluation behaviors. Purposely asking students to answer metacognitive questions afforded them the opportunity to reflect on their thinking, thus fostering their metacognition.
\end{abstract}

The abstract nature of Chemistry necessitates that its concepts and principles be learned in an environment where students can meaningfully grasp the material to be studied. Students must be given opportunities to make use of their prior knowledge in order to construct new ones. Students must be able to discuss, negotiate and defend their solutions to problems in small group settings. If these are consistently done in the Chemistry classroom, then, meaningful learning will most likely occur.

One promising way by which students can achieve meaningful learning is by letting them engage in academic tasks designed in a constructivist environment. Constructivism is a philosophy which espouses that students must be actively engaged in their knowledge construction. Constructivism asserts that knowledge is not passively received but is actively built up by the learner (Herron \& Nurrenbern, 1999).

In the past decade, the learning of Chemistry has been investigated using constructivist lens; researchers have explored the study of chemical phenomena using constructivist principles. These researchers rationalize that constructivism is the philosophical and pedagogical bases in the learning and teaching of Chemistry (Spencer, 1999; Phelps \& Lee, 2003; Farrel, Moog \& Spencer, 1999; Towns, 1998; and Shiland, 1999). Opportunities for students to engage in reflective abstractions, where they deliberately stop and reflect on their thinking processes, how they plan and execute 
academic tasks, and how they solve problems, is consistent with a constructivist philosophy. These activities are best accomplished in small group settings (Bowen, 1994)and when students think about their own thinking, cognition and metacognition come into play (Rickey \& Stacey, 2000).

Most researchers and theorists describe metacognition, or a metacognitive system, as a series of thought processes responsible for monitoring, evaluating and regulating functioning. These functions are sometimes referred to as executive control (Marzano, 1998).

Metacognition involves three dimensions. These are knowledge about oneself, knowledge about the thinking process, and controlling of one's commitment, attitude and attention to learn new or complex tasks. Commitment is defined as a deliberate choice to adopt strategies in solving problems. The various types of knowledge important in metacognition are declarative, procedural and conditional knowledge. Declarative knowledge pertains to the facts necessary to accomplish a task, while the steps or procedures and even strategies on how a task is done fall under the domain of procedural knowledge. Conditional knowledge refers to knowing why certain strategies work, when to use them and why one strategy is better than another. (Marzano, 1998).

Controlling the thinking process involves planning [choosing a path to goals, choosing procedures], regulating [checking progress, revising paths, procedures, goals and resources] and evaluating [assessing current knowledge, setting goals, and selecting resources] (Marzano, 1998). Metacognition is differentiated from reflective thinking in the sense that reflective thinking is a more generalized construct, whereas being metacognitive is a deliberate reflection on one's own cognitive functioning (Rickey \& Stacey, 2000).

Early research on metacognition explored constructs such as metamemory \% the mind's ability to purposely store and retrieve information. Investigations pioneered by Flavell and his colleagues paved the way for further exploration of metacognition. These studies were empirical in nature and were rooted in the discipline of Cognitive Psychology (Langrehr \& Palmer, 2002).

The construct of metacognition was also investigated in the disciplines of Science and Mathematics. Beeth (1998) and Koch (2001) used metacognitive strategies in the students' study of Physics concepts. Nuthall and Alton-Lee (1995) examined how students in Science and Social Studies described their answers to test items in an achievement test. Through this, students were able to apply complex metacognitive, retrieval, deduction, and knowledge construction skills. Linking metacognition to different strategies in Mathematics such as letting students write about how they solve problems (Pugalee, 2001), conducting a training program focusing on monitoring beliefs, emotions and attitudes (Zan, 2000) and using response maps to probe students' metacognitive knowledge, strategies, and decisionmaking skills (Stillman \& Galbraith, 1998) were also explored. These studies reinforced the discipline specificity of the construct of metacognition. Then, Antoneitti, Ignazi and Perego (2000) established that students' problem solving ability is related to their metacognitive skills regardless of the nature of the academic courses they are enrolled in. This implies that metacognitive skills might not be discipline specific.

Against a backdrop of a positivist paradigm, the use of metacognitive strategies was compared with traditional conventional approaches. Oladunni (1998) found that, unlike the traditional class, the metacognitive class increased students' level of achievement. Similarly, Blank (2000) reported that students in the metacognitive classroom experienced a more permanent restructuring of their understanding.

Several studies have also linked metacognition to a constructivist framework. Goos and Galbraith (1996) investigated how students used metacognitive strategies in small group settings. Grave, Boshuzien and Schmidt (1996) examined metacognitive processes like verbal communication in groups and thinking processes in a ProblemBased Learning (PBL) setting. Using various qualitative approaches, Thomas and McRobbie 
(2001) showed that students' propensity to enhance their metacognition and learning process can be linked to the use of a constructivist framework. These studies have one thing in common: academic tasks were designed and structured to foster students' awareness of their own thinking as they learned Science concepts and ideas. Results of these studies indicate that metacognition can play a role in students' cognition and knowledge construction. Purposely reflecting on their thinking processes and problem solving strategies is an effective self-monitoring device for students in their construction of Science concepts.

This study shows how academic tasks in Chemistry can be structured and designed using constructivist principles to foster students' metacognition. How students planned, monitored and evaluated their learning as they underwent various metacognitive activities, resulting in metacognitive profiles of selected students, is presented. The possible link between students' overt metacognitive behaviors and their meaningful learning of Chemistry is likewise explored. Given these contexts, the study answers the following questions:

1. How can academic tasks in Chemistry be structured to foster metacognitive behaviors?

2. To what extent do students manifest metacognitive behaviors as they engage in metacognitive activities?

3. To what extent do students demonstrate meaningful learning of identified Chemistry concepts as they undergo metacognitive activities?

4. What are the students' insights and perceptions as they study and learn identified Chemistry concepts in a metacognitive environment?

\section{METHOD}

The study was a qualitative look at how students overtly manifested planning, monitoring and evaluating behaviors as they learned and studied identified topics in General Inorganic Chemistry anchored in a constructivist environment. Consistent with the use of qualitative lens, students' metacognitive behaviors were chronicled and documented using various sources, resulting in the generation of selected students' metacognitive profiles. Hence, a multiple case-study research design was employed where these cases were posited in the metacognitive continuum as exhibiting low, moderate and high metacognitive behaviors.

Being a qualitative study, triangulation was done and adequate time was spent collecting data, noting the importance of seeking discrepant cases. Selected metacognitive activities were videotaped for evidentiary purposes. The typology of sampling employed the use of maximum variation to represent cases illustrating the various points in the metacognitive continuum. Interview responses were verified and paraphrased by taking these data back to the participants to determine plausibility. Colleagues were regularly consulted regarding the process of the study and the congruency of emergent findings with the raw data and tentative interpretations. Detailed accounts of the methods, procedures, and decision points in the study were carried out and documented. Results were reported with rich and thick descriptions enabling the readers to determine the extent to which their situation matches the research context andwhether findings can be transferred to other learning situations (Merriam, 2002). Due to space constraints, only two metacognitive profiles (representing low and high metacognitive indexes) of the nine cases are presented in this paper.

\section{Participants}

Thirty-three female first year college students enrolled in a General Inorganic Chemistry class at St. Scholastica's College, an exclusive school for girls in Manila, Philippines, participated in this study. The class studied and learned identified topics in Chemistry through active participation in metacognitive activities for an entire semester (16 weeks). Consistent with a qualitative research design, data analysis was limited to nine cases. These nine cases were selected from a preliminary 
analysis of data to represent maximum variation (Miles \& Huberman, 1994). The mean age of the participants is eighteen (18). Only one of them is graduated from a provincial high school; the rest graduated from private high schools within Metro Manila.

\section{Metacognitive Activities}

Various activities were conceptualized, adhering as much as possible, to a constructivist paradigm. As the participants engaged in these activities, they were given opportunities to construct their knowledge while they explored, solved problems and negotiated alternative solutions to problems in small group settings. They were asked to document their metacognitive behaviors (planning, monitoring and evaluation) as they answered various metacognitive questions embedded in the different activities as "Feedback to the Activity." Their responses to these questions served as one of the data sources in describing metacognition. Table 1 contains brief descriptions of some of these activities and Figure 1 presents a sample of a metacognitive activity.

\section{Table 1.}

\section{Summary of Metacognitive Activities in Chemistry}

\begin{tabular}{|c|c|}
\hline Metacognitive Activity & Description \\
\hline $\begin{array}{l}\text { Nature, Purpose and } \\
\text { Significance of Chemistry }\end{array}$ & $\begin{array}{l}\text { The activity was designed for students to deduce the rationale } \\
\text { and purpose of studying Chemistry from a critical analysis of labels } \\
\text { of consumer products. }\end{array}$ \\
\hline Fundamental Quantities & $\begin{array}{l}\text { Students asked questions on the four fundamental quantities (length, } \\
\text { mass, time, and temperature) in a round-robin way. An example } \\
\text { for length was "how deep is the deepest part of the Pacific Ocean". } \\
\text { In the process of asking questions on the four quantities, students } \\
\text { deduced ideas on these quantities in a constructivist fashion. }\end{array}$ \\
\hline Measurement and Conversion & $\begin{array}{l}\text { Students were given a set of problems to solve. In pairs, students } \\
\text { "think aloud" on how they solved the problem. One student was } \\
\text { allowed to think while her partner recorded all her verbalizations. } \\
\text { Then, they switch roles. }\end{array}$ \\
\hline Physical and Chemical Changes & $\begin{array}{l}\text { Students were presented with a story illustrating one's activities } \\
\text { for the day. They were asked to write a similar story identifying } \\
\text { the physical and chemical changes that had occurred as they } \\
\text { describe their day. }\end{array}$ \\
\hline The Mole Concept & $\begin{array}{l}\text { The module composed of different phases was designed in a } \\
\text { constructivist environment for students to explore, develop and } \\
\text { reinforce their understanding of the mole concept. The module } \\
\text { started with a "What's the Count Activity" simulating the counting } \\
\text { of atoms. This was followed by a conceptual development of the } \\
\text { mole concept through problem solving sessions in small group } \\
\text { settings. These were supplemented with synthesis lecture and } \\
\text { problems sets. }\end{array}$ \\
\hline
\end{tabular}




\section{Fundamental Quantities}

\section{Tasks:}

- Form cooperative learning groups of five (5)

- Using the table below, do a "round robin" way of supplying the pertinent information being asked. This means the "table" is to be filled up by one member, and then passed on to another member of the group until everyone has had the chance to fill up the table. You should have four entries per fundamental quantity.

- After everyone has finished filling up the table, the group should come up with an agreed definition or description of the fundamental quantity.

\begin{tabular}{|c|l|l|}
\hline $\begin{array}{c}\text { Fundamental } \\
\text { Quantity }\end{array}$ & $\begin{array}{l}\text { Measurement Associated with the Fundamental } \\
\text { Quantity in the form of a question }\end{array}$ & $\begin{array}{c}\text { Appropriate } \\
\text { Unit }\end{array}$ \\
\hline \multirow{5}{*}{ Length } & $\begin{array}{l}\text { Sample: How deep is the deepest part of } \\
\text { Member 1: } \\
\text { Member 2: } \\
\text { Member 4: }\end{array}$ & Meters \\
Agreed Definition: \\
(Member 5)
\end{tabular}

Feedback to the Activity:

1. What are your impressions of the activity?

2. What did you learn from the activity?

3. What problems or difficulties did you encounter?

4. If you had more time, what could you have been done differently?

\section{Figure 1. Sample of a metacognitive Activity: Fundamental Quantities}

\section{Ascertaining Students' Metacognitive}

\section{Behaviors}

The metacognitive behaviors of the participants were culled from a detailed analysis of their responses to the various "Feedback to the Activity" embedded in the different metacognitive activities. Their responses were transformed into a conceptually clustered matrix (Miles \& Huberman, 1994) using the dimensions of metacognition as the organizing variables. Judgments were made as to the extent of their planning, monitoring and evaluating behaviors using the grid outlined in Table 2. 
Table 2.

Manifestations of Metacognition

\begin{tabular}{|c|c|c|}
\hline $\begin{array}{l}\text { Dimensions of } \\
\text { Metacognition }\end{array}$ & Manifestations of the Dimension & Extent of Behavior \\
\hline Planning & $\begin{array}{l}\text { - Thinking and writing what one knows } \\
\text { and does not know } \\
\text { - Writing goals } \\
\text { - Writing to do list, listing information, and listing } \\
\text { the steps or procedures to solve a problem } \\
\text { or accomplish a task } \\
\text { - Identifying where to get information one } \\
\text { does not know } \\
\text { - Allotting a schedule or time to study or } \\
\text { accomplish a task }\end{array}$ & Low, moderate or high \\
\hline Monitoring & $\begin{array}{l}\text { - Repeatedly reading a material until one } \\
\text { can understand } \\
\text { - Using a dictionary to look up difficult words } \\
\text { - Highlighting a text that is deemed important } \\
\text { - Using graphic organizers (rewriting notes, } \\
\text { creating table and diagrams, etc.) } \\
\text { - Consulting references } \\
\text { - Reviewing solutions to sample problems } \\
\text { - Reviewing returned tests } \\
\text { - Solving additional problems } \\
\text { - Checking progress against goals or to-do list } \\
\text { - Asking a friend or somebody else for help or } \\
\text { as study partner }\end{array}$ & Low, moderate or high \\
\hline Evaluation & $\begin{array}{l}\text { - Checking against written goals or to do list if } \\
\text { everything is accomplished } \\
\text { - Reflecting on study strategies identifying what } \\
\text { worked and did not worked } \\
\text { - Assessing study strategies based on one's } \\
\text { performance on the test or quality of } \\
\text { - Aubmitted tasks. } \\
\text { - Assessing how study strategies can be applied } \\
\text { - Rewarding one self after studying or } \\
\text { accomplishing a task. }\end{array}$ & Low, moderate or high \\
\hline
\end{tabular}

Another source of data that posited the preliminary metacognitive profile of the participants was a researcher-made Metacognitive Inventory in Science (MIS). The MIS was administered at the onset of the study. Based on the literature, seven items for planning, 11 items for monitoring 
and eight items for evaluation were constructed. Three open-ended questions framed to probe deeper into the participants' metacognition were also included in the MIS. Each item in the MIS was given a score from 1 (never) to 4 (always). Their score on the MIS served as their initial metacognitive index.

To triangulate these two data sources, semistructured interviews were conducted with the nine participants. The interviews were conducted after the midterm examinations to allow them to have more experience with metacognitive activities. Sample questions asked during the interviews were: When you are about to accomplish a task (assignment, project or studying for a test) what do you do?; While you are studying for a test, do you check whether or not you are correct?; And after you have performed a task or studied, what do you do?

Transcribed interview data were paraphrased, condensed, summarized and transformed into a data matrix. Holistic accounts of the participants' metacognitive behaviors supplemented their metacognitive profiles.

\section{Meaningful Learning}

A data source for meaningful learning was obtained from the participants' responses to reflective questions included in their various portfolio elements. They were asked to gather tangible pieces of evidence (artifacts) that demonstrated the knowledge and skills being targeted by the portfolio element. In this study, the portfolio elements were "Solve a Problem," "Design an Experiment," "Analyze a Result," "Group Effort in Problem Solving," "Identify a Misconception," "Evolution of a Concept," "Show Growth or Improvement," and "Defend a Position." The participants had the option to choose five of these seven portfolio elements. Their responses to the question, "explain what you have learned from this portfolio element" extracted from the different portfolio entries as well as holistic evaluation of their portfolios were condensed, paraphrased and summarized. These summaries served as the basis for describing the extent of meaningful learning in this study.

\section{Students' Perceptions and Insights on the Various Metacognitive Activities}

The participants' perceptions, insights, and realizations as they engaged in the various metacognitive activities were elicited using a Questionnaire on the various Metacognitive Activities (QMA). The QMA contained three open-ended questions framed to identify their most preferred activities, the extent of their metacognitive behaviors and their evaluations of repeatedly answering the "Feedback to the Activity" included in the different metacognitive templates. Sample questions asked were the following: What activities in your Chemistry class do you remember the most?; Why are these activities worth remembering?; After all the activities you have had in Chemistry, have you become aware of your thinking process?; And how has answering the "Feedback to the Activity" included in all the activities in your Chemistry classes helped you?

\section{RESULTS}

\section{Structuring Academic Tasks in a Constructivist Environment}

In this study, the different Chemistry topics were purposely chosen to reflect a macroscopic view of the properties of matter. Because of the abstract nature of chemical concepts and principles, the students' explorations of chemical phenomena must start from something they can readily see and experience. Hence the sequence of topics is "Introduction to Chemistry," "Matter and its Properties," "Atoms, Molecules and Ions," "Stoichiometry," and "Gases." Various activities anchored on these topics were conceptualized adhering as much as possible to constructivist principles.

Given these contexts, activities were planned for students to utilize their prior knowledge as they explored, developed and reinforced their 
understanding of the chemical principles being studied. Based on the degree of difficulty of the topic, some activities were designed where an output was submitted at the end of the class period. An example of this was an activity on Fundamental Quantities, a relatively easy topic. The objective of this activity was to simply lead the students to an awareness of what "kinds of measurement" are associated with the fundamental quantity (length, mass, time and temperature) using their experiences as sources of input in a cooperative learning environment (round robin). Thus, at the end of the class session, the idea of fundamental quantities was explored and developed without the benefit of a teacher's lecture.

Some activities necessitated that students spend time to complete the tasks at hand. Students needed to consult references and discuss with peers on how best to accomplish these tasks. Thus, these activities, still within a constructivist's framework, where structured in such a way that tasks are open-ended where only a problem prompt was provided, and students had opportunities to apply previous learning to complete these tasks. An example of this activity was the concept mapping activity. Given a self-contained module on properties of matter and related topics, students were asked to construct concept maps on how best they understood the material. Another example is the activity where students create their own stories describing their day illustrating physical and chemical changes.

A topic that was particularly difficult was the mole concept. A series of activities and concept development exercises were designed so that students get to explore, develop and reinforce their knowledge on the mole concept. Students' exploration of this topic took several class sessions. They were inductively guided for them to intuit

Table 3.

Task Analysis of Some Metacognitive Activities

\begin{tabular}{|c|c|c|c|c|}
\hline $\begin{array}{c}\text { Metacognitive } \\
\text { Activity }\end{array}$ & Targeted Skills & $\begin{array}{l}\text { Degree of } \\
\text { Difficulty of } \\
\text { the Task }{ }^{1}\end{array}$ & $\begin{array}{l}\text { Time Allotted } \\
\text { to Complete } \\
\text { the Task }\end{array}$ & $\begin{array}{c}\text { Adherence to } \\
\text { Constructivist } \\
\text { Principles }^{3}\end{array}$ \\
\hline $\begin{array}{l}\text { Fundamental } \\
\text { Quantities }\end{array}$ & $\begin{array}{l}\text { Deduce "ideas" on length, } \\
\text { mass, time and temperature } \\
\text { through asking questions }\end{array}$ & Easy & Short Time & Limited Extent \\
\hline Concept Mapping & $\begin{array}{l}\text { Summarize concepts } \\
\text { demonstrating links amongst } \\
\text { and between concepts }\end{array}$ & $\begin{array}{l}\text { Moderately } \\
\text { Difficult }\end{array}$ & Moderate Time & Extensive \\
\hline $\begin{array}{l}\text { Problem Set on } \\
\text { Conversion }\end{array}$ & $\begin{array}{l}\text { Demonstrate conceptual and } \\
\text { algorithmic understanding on } \\
\text { conversion applying the } \\
\text { skills of dimensional analysis }\end{array}$ & Difficult & Moderate Time & $\begin{array}{l}\text { Moderate } \\
\text { Extent }\end{array}$ \\
\hline $\begin{array}{l}\text { The Mole } \\
\text { Concept }\end{array}$ & $\begin{array}{l}\text { Deduce the conceptual and } \\
\text { operational definitions of the } \\
\text { mole and apply this } \\
\text { knowledge in algorithmic } \\
\text { conceptual problems }\end{array}$ & Difficult & Extended Time & Extensive \\
\hline
\end{tabular}


Table 4.

Results from the Metacognitive Inventory in Science (MIS) Dimensions ${ }^{4}$

\begin{tabular}{|c|c|c|c|c|}
\hline Dimension & Typical Item & $\alpha$ - Reliability & $\operatorname{Mean}^{5}(N=33)$ & $\begin{array}{l}\text { Standard } \\
\text { Deviation }\end{array}$ \\
\hline \multirow[t]{2}{*}{ Planning } & $\begin{array}{l}\text { I think and write what I } \\
\text { know and do not know } \\
\text { about the material I need to } \\
\text { study or on the task at hand. }\end{array}$ & 0.55 & 2.85 & 0.33 \\
\hline & $\begin{array}{l}\text { I list down the information } \\
\text { necessary to help me study } \\
\text { or accomplish the task } \\
\text { (assignment, project or any } \\
\text { other school requirement) }\end{array}$ & & & \\
\hline \multirow[t]{2}{*}{ Monitoring } & $\begin{array}{l}\text { I solve additional problems } \\
\text { found in the textbook or any } \\
\text { other reference material. }\end{array}$ & 0.71 & 2.95 & 0.41 \\
\hline & $\begin{array}{l}\text { I look at my "to do" list to } \\
\text { see whether I'm doing the } \\
\text { things I needed to do }\end{array}$ & & & \\
\hline \multirow[t]{2}{*}{ Evaluation } & $\begin{array}{l}\text { I look at my written goals to } \\
\text { see whether I have } \\
\text { accomplished what I have } \\
\text { set out to do }\end{array}$ & 0.77 & 2.80 & 0.18 \\
\hline & $\begin{array}{l}\text { I reflect on the "success" of } \\
\text { my study strategies based } \\
\text { on how well I did on an } \\
\text { examination or the quality of } \\
\text { output (assignment, project } \\
\text { or any other school } \\
\text { requirement) I have } \\
\text { produced. }\end{array}$ & & & \\
\hline Overall & & 0.88 & 2.88 & 0.33 \\
\hline
\end{tabular}

and deduce the operational and conceptual definitions of the mole. Because the mole concept is one of the most abstract concepts in Chemistry, a synthesis lecture was given but only to clarify and reinforce the knowledge and skills students already possess.

Table 3 presents a tasks analysis matrix for selected metacognitive activities employed in the study. 
Table 5.

Initial Metacognitive Profiles of the Nine Cases based only on the MIS

\begin{tabular}{|ccc|}
\hline Metacognitive Index & Cases (Pseudonyms) & MIS Score \\
\hline \multirow{2}{*}{ Low } & Andrea & 2.01 \\
& Francine & 2.12 \\
& & \\
Moderate & Christy & 3.04 \\
& Donna & 2.62 \\
& Emily & 2.75 \\
& Hannah & 2.63 \\
& & 3.64 \\
High & Barbara & 3.57 \\
& Geraldine & 3.29 \\
\hline
\end{tabular}

Topics anchored on these activities had varying levels of difficulty. Because of this, time spent by students to accomplish the different tasks associated with the activities also varied. There were tasks that were completed at the end of the class session and some tasks or outputs submitted after students had time to consult references or discuss with peers. A topic like that of the mole concept was explored, and developed as students engaged in structured activities that lasted for several class sessions. Because of the inherent nature or degree of difficulty of the topics, strict adherence of all these activities to constructivist principles was not possible. Activities therefore have varying levels of adherence to constructivism.

Thus, these factors: the difficulty of the tasks; time spent in completing these tasks; and their adherence to constructivist principles affected the extent to which students demonstrated overt metacognitive behaviors.

\section{Students' Metacognitive Profiles}

An initial metacognitive profile of the participants was generated using scores obtained from the Metacognitive Inventory in Science (MIS). In this study, the construct of metacognition was assumed to be a continuum and thus, it is possible to posit cases on the various points of this continuum. The overall mean calculated from the administration of the MIS is 2.88 with a standard deviation of 0.33 . Thus, taking one standard deviation below and above the mean, a range of 2.55-3.20 was used to posit participants (cases) in the "moderate" section of the metacognitive continuum. Given this premise, participants were judged as manifesting high metacognitive behavior if they obtained a metacognitive index of 3.21 - 4.00; whereas those who obtained a metacognitive index from 1.00-2.54 were initially judged as exhibiting low metacognitive behavior. The dimensions, typical items and reliability estimates of the MIS are found in Table 4. Table 5 gives the initial metacognitive profile of the nine participants based only on the MIS.

Metacognition is defined in this study as the various ways and processes by which students plan, monitor, and evaluate their own learning. On the other hand, Planning behaviors are the steps, procedures or activities that students engage in as they are about to study or accomplish tasks. Monitoring behaviors are overt manifestations where students check their progress, revise their procedures or goals and adjust their study strategies. Meanwhile, Evaluation behaviors focus on students' accounts of how they assessed their learning. In order to probe deeper into the participants' metacognitive behaviors, they were repeatedly asked to answer questions (as 
Andrea (Low Metacognitive Index)

Andrea has very poor planning skills. For instance, in the" Powers of Ten Activity”, she claimed that the task was not clear and that she did not understand the direction on how the task should be accomplished. In another activity, Classifying Buttons, she was asked how she arrived at her classification scheme. Andrea had no response to this question.

Part of planning skills is to identify the learning goals of a particular task or activity. When asked about her learning goals in the Mole Concept activity, Andrea wrote, "How many are some objects even if we don't count them." In context, Andrea is referring to the "What's the Count" activity, wherein, popcorn kernels, white, or red beans were used to simulate very small particles. In this activity, students were given a problem prompt to devise ways to count popcorn kernels, white or red beans without actually counting. It can be inferred that Andrea had difficulty articulating the kind of goals that can be associated with her learning of the mole concept. She did not demonstrate higher cognitive functioning, she could only recall to a limited extent only one aspect of the mole concept. It is evident that as Andrea went through the various activities, even in small group settings; her planning skills did not improve. Overt planning behaviors were not evident.

The monitoring skills of Andrea are also poor. By her own admission, in the "Powers of Ten Activity", she wrote that she had difficulty with finding pictures that illustrated relative sizes but is not certain whether or not she was correct. Andrea could admit to a certain extent her own limitations; she is also not confident of her own abilities. In her responses to the questions on which problems were difficult to solve (problem sets on dimensional analysis, stoichiometry, and gases), Andrea was able to identify the problems that were difficult; but she could not substantiate why she found the problem difficult.

Andrea's assessment of what she had learned is indicative of not being a reflective learner. She did not check her progress against her goals or her to do list because there were no checklists or to do list in the first place. Neither did she demonstrate any indication that she adjusted her study strategies to solve a problem. Andrea's poor assessment of her learning is evidenced by the absence of supporting statements to substantiate her claim. For example, when asked how she solved the problem, she simply wrote, "I analyzed the problem." Andrea, throughout her responses, used "analyze" without explaining what it meant, and without giving details on how she solved the problem. Thus, Andrea is placed in the low end of the metacognitive continuum. Her metacognitive skills did not progress during the course of the study.

Figure 2.

Metacognitive profile of Andrea (Low metacognitive Index)

"Feedback to the Activity") formulated to make them deliberately think about how they planned certain tasks, and how they monitored and evaluated their learning. Responses to these questions coupled with interview data served as the basis in generating metacognitive profiles of the nine participants. Figures 2 and 3 give the metacognitive profiles of*Andrea and *Irene.

\section{Meaningful Learning}

Students' portfolios is a window by which one can look into their meaningful learning of Chemistry. If students find applicability of the lessons they have studied, if they can use their prior knowledge to construct new ones and show strong evidence that they have learned beyond the acquisition of content knowledge, then 
Irene (High Metacognitive Index)

Irene's goals in the various activities were: "to identify physical and chemical changes in a given situation, pay attention to simple details in one's life; to know and understand the module [on matter and its properties] and to find ways to present these topics in a creative and understandable way; to fully understand the meaning of the mole concept, knowing its importance, and determining the use of the concept and relating it to other topics." Thus, Irene, in her mind, had a definite direction of where she wanted to go. These are manifestations of good planning skills.

Irene claimed that some of the problems were difficult, particularly the earth problem, because this needed a lot of analysis and its solution is not a straightforward conversion. To solve this problem, Irene scanned her old notes and consulted other references, and sought the help of her classmates. As Irene constructed her concept map on matter and its properties, she claimed that for her to successfully come up with a good map she summarized the main points and details of the module, and then plotted the map based on this summary. As Irene solved problems related to the mole concept and percentage composition, she claimed that she knew she was correct by "comparing her solution to the given solutions provided by the professor and of her classmates, by consulting additional references and solving additional problems." Particularly in the mole concept, Irene evaluated the correctness of her solution to the problem by "relating the solution to the two tables." The two tables being referred to were the use of two heuristic devices by which students, in a constructivist fashion, deduced the operational and conceptual definitions of the mole.

Irene had opportunities to self-assess her learning, to reflect on the strengths and limitations of her output and propose ways that these can be improved. These are some of her realizations: "creating questions was challenging and helped me expand my mind and understand the fundamental quantities (Fundamental Quantities); I learned that analysis, patience, good memory, and the ability to communicate with a partner are important; and I realized the importance of a flowchart in illustrating the classification scheme" (Powers of Ten). These realizations are beyond the acquisition of content knowledge

Irene also demonstrated self-efficacy behaviors; she made very good judgments on her capacity to perform the task. She was confident in the quality of her output. When asked what she could have done differently on the problem solving activity on conversion, she claimed that she "would not change anything because there is nothing in the activity that she regretted doing." She claimed to solve the problems "based on her own understanding." In the Elements, Compounds and Mixtures activity, Irene wrote, "I could have learned more if I have read the module more clearly, and paid attention to the important components of the module." Similarly as Irene wrote her story on physical and chemical changes, this is what she reported "If had more time, I would have created a much more interesting story, because my story was quite dull and boring." In constructing a concept map, Irene admitted that she should have drawn a more creative concept map. Thus, Irene was able to identify how her work could be improved and in the process self-assessed her learning.

\section{Figure 3.}

\section{Metacognitive Profile of Irene (High Metacognitive Index)}


Table 6.

Analysis of Portfolios of Andrea and Irene

\section{Case \\ Attributes of Portfolios}

Andrea Andrea did not follow the set guidelines in completing her portfolio.

Instead of gathering materials (quizzes, problem sets, or any other school requirement) that she already had, she made mini reports on various topics. She made reports on the atomic theory, three laws of chemical combination, matter and its properties, etc., focusing on content. She failed to show how the various school requirements (artifacts) supported the different portfolio elements. Andrea did not understand what she needed to accomplish

Irene Irene had many insights and realizations as she completed the various portfolio elements. Her explanations of her learning were deliberately focused on her learning other things beyond the acquisition of content knowledge. She acknowledged that group work and teamwork were important in accomplishing tasks. This was her realization as she described how the buttons activity illustrated her skill in solving a problem. Using the powers of ten and number line scale output, Irene claimed that this activity helped foster her creativity and diligence. She further asserted that "exceeding beyond my limitations" was what she realized in this activity. Irene realized why Chemistry is not a boring subject because "everyday is a new discovery". Using the various problem sets, Irene realized that she had improved on her learning. She also learned to be "more serious and determined if I want learn and achieve something"

without doubt, these are manifestations of meaningful learning.

The participants in this study were asked to gather tangible pieces of evidence (artifacts) to illustrate that they have attained the knowledge and skills (competencies) being targeted by a portfolio element ("Analyze a Result", "Solve a Problem", etc.). As they gather materials to satisfy a portfolio element, they were asked to explain what they had learned. They were also asked to take a holistic look at the different portfolio elements and judge whether such artifacts satisfy the attributes of the portfolio element. Table 6 gives a summary of the analysis on the portfolios of *Andrea and *Irene.

Note that *Andrea failed to show samples of her work that satisfactorily illustrated the various portfolio elements. One can argue that there is inherent learning as she made mini reports on the various topics, but this did not provide an opportunity for her to reflect on the progression of her work. Thus, she was not able to demonstrate meaningful learning using a portfolio assessment.

*Irene manifested meaningful learning by giving convincing explanations of not only her acquisition of content knowledge but other learning as well. She methodically spelled out her insights and realizations as she chose samples of her work to satisfy the different portfolio elements. She found applicability of her Chemistry lessons in her daily life. *Irene acknowledged that "thinking in her own way" was helpful in gaining deeper understanding of the material. She had successfully shown that her knowledge and skills have improved; hence, meaningful learning had occurred.

\section{Students' Insights and Realizations on the Various Metacognitive Activities}

When asked what activities in their Chemistry lecture classes they remembered the most, eight out of the nine participants mentioned that it was 
Table 7.

Excerpts of Insights and Realizations of Andrea and Irene

\begin{tabular}{|c|c|c|c|c|}
\hline $\begin{array}{c}\text { Case } \\
\text { (Pseudonyms) }\end{array}$ & $\begin{array}{l}\text { Awareness of } \\
\text { One's Thinking }\end{array}$ & $\begin{array}{l}\text { Monitoring } \\
\text { Statements }\end{array}$ & $\begin{array}{l}\text { Evaluation } \\
\text { Statements }\end{array}$ & $\begin{array}{l}\text { Statements on } \\
\text { "Feedback to } \\
\text { the Activity" }\end{array}$ \\
\hline Andrea & $\begin{array}{l}\text { I am not aware of } \\
\text { my thinking } \\
\text { because I do not } \\
\text { participate in class }\end{array}$ & $\begin{array}{l}\text { I jot down notes, } \\
\text { make a summary } \\
\text { of the lessons and } \\
\text { refer to Chemistry } \\
\text { books }\end{array}$ & $\begin{array}{l}\text { I study what I have } \\
\text { learned and } \\
\text { compared it with } \\
\text { my classmates }\end{array}$ & $\begin{array}{l}\text { The feedback } \\
\text { helped me review } \\
\text { what I have } \\
\text { learned in every } \\
\text { class activity }\end{array}$ \\
\hline Irene & $\begin{array}{l}\text { I have discovered } \\
\text { my own abilities, } \\
\text { my strengths and } \\
\text { weaknesses and } \\
\text { the ability to } \\
\text { resolve problems I } \\
\text { have difficulty with. }\end{array}$ & $\begin{array}{l}\text { I know if I have } \\
\text { improved in a } \\
\text { certain lesson or } \\
\text { really learned } \\
\text { something from the } \\
\text { lecture }\end{array}$ & $\begin{array}{l}\text { I have evaluated } \\
\text { myself on the } \\
\text { things I have done } \\
\text { and accomplished. }\end{array}$ & $\begin{array}{l}\text { Answering the } \\
\text { feedback helped } \\
\text { me realize what I } \\
\text { have learned and } \\
\text { what I should be } \\
\text { learning in the } \\
\text { next lesson. }\end{array}$ \\
\hline
\end{tabular}

the mole concept module that they remembered the most. They found the "What's the Count" activity fun and interesting. They liked the idea of brainstorming and planning on how to "count" small objects without actually counting them. A student admitted that because of the activity, she had corrected her misconception about the mole concept and this was precisely why she remembered this lesson. Table 7 gives excerpts of insights and realizations of Andrea and Irene

Note that *Andrea admitted that even after being exposed to all the metacognitive activities, she was not aware of her thinking because she claims to have not participated. *Andrea acknowledged that she jotted down notes, and consulted Chemistry books but there is very little evidence that these are metacognitive in nature. These activities were accomplished, perhaps to fulfill the requirements of the subject. To a limited extent, by her own admission, letting her deliberately pause and answer the "Feedback to the Activity" helped her review what she had learned. This in effect gave her opportunities to reflect on her thinking, but still she did not demonstrate being reflective on her own accord.

*Irene was judged as exhibiting high metacognitive behaviors. Her insights and realizations support this judgment. She admitted that because of her engagement in the various activities, she had learned to reason out and defend her answers. She also asserted that she had been checking, monitoring and evaluating her learning. These behaviors became increasingly evident as a result of repeatedly answering the various "Feedback to the Activity.".

Thus, the various activities as a whole were judged as opportunities for students to engage in reflective abstractions. Students admitted that the design and structure of the activities enabled them to be aware of their own thinking. The way the lessons are introduced, developed and reinforced, consistent with a constructivist paradigm, facilitated the monitoring and evaluation the students' learning. Through these activities, students claim to learn on their own.

Deliberately answering the "Feedback to the Activity" gave the students the time to reflect on 
their strengths and weaknesses as learners as well as the opportunity to think of ways to improve on their knowledge and skills and how these can be applied to other learning context. Without doubt, the purposeful engagement in these activities paved the way for students to be metacognitive.

\section{DISCUSSION}

\section{Metacognitive Activities}

In this study, various metacognitive activities were designed adhering as much as possible, to constructivist principles. These activities were designed for students to inductively construct their knowledge either from given empirical evidence or by letting them use their prior knowledge as they develop their understanding of the different chemical concepts. For topics that were judged as difficult, a class lecture followed the activity. Take the case of a topic on conversion. Here, the students were initially given a problem set and in small group settings, were asked to solve problems prior to a formal lecture. As students solved the problem, they discussed, argued, defended and negotiated their answers to the problems. A thinkaloud method was employed as students discussed the solutions to the given problems. During the process, students were conscious of their thinking and how they solved the problems. This demonstrates metacognitive behavior. Activities like straightforward solution of problems (problem sets on stoichiometry and gases) provided limited opportunities for students to construct knowledge since these activities or exercises are designed to reinforce problem solving skills. The ability for students to apply algorithmic knowledge and skills are equally important in the students' learning of Chemistry. Letting students discuss the solutions to the problems in small group settings gave them the opportunity to demonstrate metacognitive behavior even to a limited extent. One activity that students enjoyed doing was writing a story that described their typical day using examples of physical and chemical changes. This activity afforded the students to demonstrate their planning, monitoring and evaluation behaviors because they were given time to brainstorm and come up with their stories.

An activity that had all the elements of constructivism was the run of the mole concept module. In this activity, students were led to the operational and conceptual definition of the mole by performing the "What's the Count" activity. They were given a problem prompt, without explicit directions, on how they could use weights to count small objects like popcorn kernels, red or white beans. Students brainstormed on and planned the most efficient and practical way of accomplishing the task. The teacher served only as a facilitator as students completed their tasks. Given two heuristics relating the mass of one mole to its atomic weight or molecular weight and Avogadro's number, students deduced the operational definition of the mole. Without the benefit of a teacher's lecture, students solved problems on the mole concept, in small group settings, debating and negotiating solutions to problems. After all these activities, only then was a "synthesis lecture" given. Thus, this activity, because of the nature of its design and structure, allowed students to construct knowledge about the mole concept. In the process, metacognitive behaviors were exhibited.

The different metacognitive activities provided varying degrees of opportunities through which students' metacognitive behaviors could be fostered. It is reasonable to infer that the perceived difficulty of the tasks (as reported by students in their responses from the "Feedback to the Activity") could affect the their extent of planning, monitoring and evaluation of their learning. Another factor that could affect students' demonstration of their metacognitive behaviors was the time allotted in the completion of tasks. A prolonged engagement in activities that let students think about their thinking would certainly encourage metacognition as compared to undergoing tasks where an output is needed at the end of the class session. Finally, academic tasks designed and structured to strictly adhere to constructivist principles promoted targeted metacognitive 
behaviors. In this study, the mole concept module contained ample opportunities for students to construct their knowledge. In the process of active engagement in their learning, students demonstrated planning, monitoring and evaluation behaviors.

Note that it is the interplay of these various activities that could foster students' metacognitive behaviors. Being aware of one's own thinking can not be developed overnight. Time must be spent for students to demonstrate this skill. Students must be actively engaged in activities where they can discuss, negotiate solutions to problems and construct their knowledge for a prolonged period of time. Activities must be structured such that students can plan, monitor and evaluate their behaviors. If these are consistently done in the Chemistry classroom, students can overtly manifest metacognitive behavior leading to meaningful learning.

\section{The Case of Andrea ${ }^{6}$}

*Andrea exhibited limited metacognitive behaviors. She is not aware of her own thinking. She had difficulty articulating her thoughts. She could not provide supporting statements to assert her claims. There was very little evidence she could offer to support her thinking processes. When asked whether she was checking the progress of her work, she responded that sometimes she does not. She further claimed that when she "is through with the assignment, that's it". Further, she reports that "sometimes, she checked her answers to the problems by analyzing them," but when probed what she meant by "analyzing," she was unable to explain. Andrea exhibited low metacognitive behaviors even if activities were provided for her to reflect on her learning. The fact that she claimed that she had been reflecting on her learning might only be a result of her compliance with the academic requirements of the subject. Andrea was not able to show supporting details for her choice of study strategies. This lack of supporting details to expound on her belief system is an indication that such a belief system is not overtly manifested and, thus, is not integrated within her cognitive schema (Hogan, 2000). The skill of being reflective, pausing to self-assess and adjusting study strategies were not evident during the course of the study. Thus, Andrea exhibited low metacognitive behaviors throughout the study.

In this study, students' metacognitive behaviors were linked to the quality of their portfolios. Andrea did not demonstrate meaningful learning as evidenced by her low scores on the various pencil-and paper tests. She also did not follow the guidelines for accomplishing her portfolio. She failed to demonstrate how her various works (assignments, quizzes, projects, etc.) satisfied the identified portfolio elements. From an examination of her portfolio entries, there was very little evidence that she reflected on her strengths and weaknesses through her own judgment of her works. Thus, Andrea's poor metacognitive behaviors did not bring about meaningful learning.

\section{The Case of *Irene}

On the other end of the metacognitive continuum, *Irene manifested high metacognitive behaviors. She is constantly aware of her thinking process prior to studying or accomplishing a task as well as while she is on-task. She evaluated her learning, concretely listing her realizations and ways to improve the quality of her output.

Writing learning goals is a manifestation that one can identify the knowledge and skills that should be attained after a learning task. These goals are one's guideposts in accomplishing a task; thus, how goals are written can be a window into one's planning skills. Irene demonstrated planning skills as shown in her responses to the "Feedback to the Activity", from her portfolio entries and from interview data. The way she wrote her goals showed that she learns for understanding. She was not satisfied with simple rote learning; she knew that the concepts learned should be understood and these concepts should be related to other concepts.

In the interview with Irene, she claimed that she solved the most difficult problems first. In solving problems successfully, she is aware that she has the knowledge and analytical skills to solve the problem. She further asserted that when she 
could not solve a problem, then it was a sign that more information was needed. Irene confessed that when she could not solve the problem, she consulted references or look for solved sample problems. When asked how she knew she was on the right track when solving a problem, she responded by citing a problem she solved on Boyle's Law. She knew that she was correct when she arrived at the desired unit called forth in the problem. Irene is self-motivated. She admitted that before going to the mall, she would try to study first or complete an assignment.

Throughout the study, Irene consistently demonstrated that she was actively aware of her thinking. The way she wrote her learning goals indicated that she is a deep learner and that she was not satisfied with mere acquisition of facts. She learns to understand. She was able to systematically identify the difficulties she had encountered and methodically sought ways to address these difficulties.

Irene also scored well on the various penciland-paper tests indicative of her higher cognitive functioning at work. She was able to solve the more difficult problems in the various long tests and applied her prior knowledge as she constructed new ones. She was actively involved in her learning as she defended and negotiated solutions to problems in small group settings. Irene's portfolio entries (quizzes, assignments and projects) were evident of her deeper understanding of the studied Chemistry concepts. Through her portfolio, she articulated insights and realizations beyond the acquisition of content knowledge. In doing so, meaning is created in her learning. Irene's high metacognitive behaviors brought about meaningful learning.

\section{CONCLUSION}

Prolonged engagement in classroom activities designed in a constructivist environment allow students to link prior knowledge with newly constructed knowledge as they work in small group settings. In the process of knowledge construction, they manifest overt planning, monitoring and evaluating behaviors. This is turn, fosters their metacognition. The students in this study reported that the various activities helped them learn Chemistry materials meaningfully. They liked the idea that lessons were not presented in a straightforward manner and that the different activities were fun, enjoyable, and interesting. Deliberately asking these students to answer metacognitive questions afforded them the opportunity to reflect on their strengths and weaknesses as learners and how these learning can be applied to other learning contexts.

However, prolonged engagement in activities designed and structured in a constructivist environment to give students opportunities to reflect on their thinking does not necessarily foster the targeted metacognitive behaviors (as in the case of *Andrea). The perceived difficulty of the topics anchored in different activities, time spent in completing these activities and the adherence of these academic tasks to constructivist principles can affect the extent to which students could manifest overt metacognitive behaviors.

Another construct is at play here. Students have a set of beliefs or assumptions about the nature of knowing and on the process of knowing. Do students believe that Chemistry is simply a bunch of equations to solve? Do students view that learning Chemistry consists mainly of absorbing information? Do students believe that being good in Science is innate or inborn? This set of beliefs is referred to as epistemological beliefs. Whether students believe that Science concepts have wide applications outside the classroom, whether Science concepts are evolving and how these beliefs can mediate or influence metacognition are interesting points for future research.

\section{NOTES}

\footnotetext{
${ }^{1}$ Tasks were classified according to easy, moderately difficult and difficult

${ }^{2}$ Time allotted to tasks was classified according to short, moderate and extended period of time for students to complete task and engage in planning, monitoring and
} 
evaluation behaviors as necessitated by the tasks.

${ }^{3}$ Tasks were judged as adhering to constructivist principles to a limited extent, moderate extent and extensively following constructivist principles.

${ }^{4}$ Results obtained from administration of the MIS at the onset of the study.

${ }^{5}$ Items are scored 1,2,3,4 respectively for Never, Sometimes, Often and Always. A high mean corresponds to a more overt metacognitive behavior.

${ }^{6}$ Due to space constraints, only two of the cases illustrating low and high metacognitive behaviors will be discussed in this paper.

\section{REFERENCES}

Antonietti, A., Ignazi, S., \& Perego, P. (2000). Metacognitive knowledge about problem solving methods. The British Journal of Educational Psychology, 70, 1-16.

Beeth, M. (1998). Teaching for conceptual change: Using status as a metacognitive tool. Science Education, 82, 343-356.

Blank, L. (2000). A metacognitive learning cycle: A better warranty for student understanding? Science Education, 84, 486-506.

Bowen, C. (1994). Think-aloud methods in chemistry education. Journal of Chemical Education, 71 (3), 184-191.

Farrel, J., Moog, R., \& Spencer, J. (1999). A guided inquiry general chemistry course. Journal of Chemical Education, 76 (4), 570574.

Goos, M., \& Galbraith, P. (1996). Do it this way! Metacognitive strategies in collaborative mathematical problem solving. Educational Studies in Mathematics, 30, 229-260.

Grave, W., Boshuizen, H., \& Schmidt, H. (1996). Problem based learning: Cognitive and metacognitive processes during problem analysis. Instructional Science, 24, 321-341.

Herron, D., \& Nurrenbern, S. (1999). Chemical education research: Improving chemistry learning. Journal of Chemical Education, 76 (10), 1354-1531.

Koch, A. (2001). Training in metacognition and comprehension of physics text. Science Education, 85 (6), 758-768.
Langrehr, D., \& Palmer, B. (2002.) A historical perspective of metacognition: From abstraction to paradigm. Retrieved March 2, 2002, from http://garnet.acns.tsu.edu/dbl2291/metacog.html

Marzano, R. (1998). Metacognition. Retrieved March 2, 2002 from http://academic.pg.cc md.us-wpeirce/MCCCTR/metaco-1.html

Merriam, S. (2002). Qualitative research in practice. San Francisco: Jossey-Bass.

Miles, M., \& Huberman, A. (1994). An expanded sourcebook. Qualitative data analysis. Thousand Oaks, CA: Sage Publications.

Nuthall, G., \& Alton-Lee, A. (1995). Assessing classroom learning: How students use their knowledge and experience to answer classroom achievement test questions in science and social studies. American Educational Research Journal, 32 (1), 185-223.

Oladunni, M. (1998). An experimental study on the effectiveness of metacognitive and heuristic problem solving techniques on computational performance of students in mathematics. International Journal of Mathematical Education in Science and Technology, 29 (6), 867-874.

Phelps, A., \& Lee, C., (2003). The power of practice: What students learn from how we teach. Journal of Chemical Education, 80 (7), 829.

Pugalee, D. (2001). Writing, mathematics, and metacognition: Looking for connection through students' work in mathematical problem solving. School Science and Mathematics, 101 (5), 236-245.

Rickey, D., \& Stacey, A. (2000). The role of metacognition in learning chemistry. Journal of Chemical Education, 77 (7), 915-920.

Shiland, T. (1999). Constructivism: The implications for laboratory work. Journal of Chemical Education, 76 (1), 107-109.

Spencer, J., (1999). New directions in teaching chemistry: A philosophical and pedagogical basis. Journal of Chemical Education, 76 (4), 566-569. 
Stillman, G., \& Galbraith, P. (1998). Applying mathematics with real world connections: Metacognitive characteristics of secondary students. Educational Studies in Mathematics, 36 (2), 157-195.

Thomas, G., \& McRobbie, C. (2001). Using metaphor for learning to improve students' metacognition in the chemistry classroom. Journal of Research in Science Teaching, 38 (2), 222-259.
Towns, M. (1998). How do I get my students to work together? Getting cooperative learning started. Journal of Chemical Education, 75 (1), 67-69.

Zan, R. (2000). A metacognitive intervention in mathematics at university. International Journal of Mathematical Education in Science and Technology, 31 (1), 143-150. 